\title{
Lymphopenia assessment in ICU patients and relationship with mortality
}

\author{
R Gutierrez-Rodriguez ${ }^{1}$, E Aguilar-Alonso², MD Arias-Verdu ${ }^{* *}$, E Castillo-Lorente $^{3}$, C Lopez-Caler ${ }^{1}$, M Rojas-Amezcua ${ }^{2}$ \\ , C De la Fuente-Martos², R Rivera-Fernandez', G Quesada-Garcia' \\ From ESICM LIVES 2015 \\ Berlin, Germany. 3-7 October 2015
}

\section{Introduction}

White blood cell count is a parameter that is included in many scoring systems. Previous studies based on acute coronary syndrome are demonstrated that the ratio of neutrophils to lymphocytes is related to mortality. The relationship between lymphocytes count and mortality is unknown in critically ill patients.

\section{Objectives}

To assess the relationship between ICU mortality and disturbance in the lymphocytes count.

\section{Methods}

Multicenter case-control study nested in a cohort. Patients hospitalized to a period of four months in the ICU of the two hospital (University Clinical -Malaga- and Infanta Margarita- Cabra, Córdoba-) are included. We have studied all deaths and a random sample (1 of 5) of the survivors.

\section{Results}

226 patients (178 Malaga, 48 Cabra). 89 cases (deaths). And 138 controls that are the random sample of survivors. Mean age was $63.39 \pm 14.04$ years. The severity assessed by SAPS-3 in $48.84 \pm 15.39$ points.

The deaths present at admission leukocytes count 13614 \pm 6137 vs. $10212 \pm 4759$ of the controls $(\mathrm{p}<0.001)$. The deaths also present on admission greater neutrophils count $10813 \pm 6258$ vs $7823 \pm 4396(\mathrm{p}<0.001)$ and lower lymphocytes count $1194 \pm 826$ vs $1471 \pm 1355$ ( $<<0.001$ ). The ratio of neutrophils and lymphocytes increased in deaths $(15.55 \pm 24.14$ vs $8.38 \pm 7.54, \mathrm{p}<0.001)$.
We collect the lowest lymphocytes count throughout all ICU stay and the deaths have lower lymphocyte count that survivors $(768 \pm 494$ vs $1120 \pm 893, \mathrm{p}<0.001)$. Multivariate analysis showed that variable most related with mortality is the lowest lymphocytes count. The $47.2 \%$ of deaths patients had lymphocytes count less that 600 in the analytical with lower lymphocyte count, compared to $23.4 \%$ of the survivors $(\mathrm{p}<0.001)$, OR: 2.93 (1.65-5.21).

\section{Conclusions}

The mortality of ICU patients is associated with leukocytosis, neutrophilia, lymphopenia and high ratio of neutrophils and lymphocytes. The deaths usually have very low lymphocytes count.

\footnotetext{
Authors' details

${ }^{1}$ Regional University Hospital, Intensive Care, Malaga, Spain. ${ }^{2}$ Infanta Margarita Hospital, Intensive Care, Cabra, Spain. ${ }^{3} \mathrm{Hospital}$

Neurotraumatologico, Intensive Care, Jaen, Spain.
}

Published: 1 October 2015

\section{References}

- Akilli NB, Yortanlı M, Mutlu H, et al: Prognostic importance of neutrophillymphocyte ratio in critically ill patients: short- and long-term outcomes. Am J Emerg Med 2014, 32(12):1476-80, Dec.

2. Tamhane UU, Aneja S, Montgomery D, et al: Association between admission neutrophil to lymphocyte ratio and outcomes in patients with acute coronary syndrome. Am J Cardiol 2008, 102:653-657.

doi:10.1186/2197-425X-3-S1-A340

Cite this article as: Gutierrez-Rodriguez et al.: Lymphopenia assessment in ICU patients and relationship with mortality. Intensive Care Medicine Experimental 2015 3(Suppl 1):A340. 